\title{
Publisher Correction: Pressure tuning of light-induced superconductivity in $\mathrm{K}_{3} \mathrm{C}_{60}$
}

\author{
A. Cantaluppi, M. Buzzi, G. Jotzu (D), D. Nicoletti, M. Mitrano D, D. Pontiroli (D, M. Riccò, A. Perucchi, P. Di Pietro \\ and A. Cavalleri iD
}

Correction to: Nature Physics https://doi.org/10.1038/s41567-018-0134-8, published online 7 May 2018.

In the version of this Article originally published, the superscript 6 indicating equally contributing authors was missing from M. Buzzi. This has now been corrected.

Published online: 15 May 2018

https://doi.org/10.1038/s41567-018-0167-z

\section{Publisher Correction: Magnetic configuration effects on the Wendelstein 7-X stellarator}

A. Dinklage (ID, C. D. Beidler, P. Helander, G. Fuchert, H. Maaßberg, K. Rahbarnia, T. Sunn Pedersen, Y. Turkin,

R. C. Wolf (D), A. Alonso, T. Andreeva (D), B. Blackwell, S. Bozhenkov (D), B. Buttenschön, A. Czarnecka, F. Effenberg (iD,

Y. Feng, J. Geiger, M. Hirsch, U. Höfel (D, M. Jakubowski, T. Klinger, J. Knauer, G. Kocsis, A. Krämer-Flecken (D),

M. Kubkowska, A. Langenberg, H. P. Laqua, N. Marushchenko, A. Mollén (D, U. Neuner, H. Niemann, E. Pasch, N. Pablant D, L. Rudischhauser (D), H. M. Smith, O. Schmitz, T. Stange, T. Szepesi, G. Weir (D), T. Windisch, G. A. Wurden iD, D. Zhang and the W7-X Team

Correction to: Nature Physics https://doi.org/10.1038/s41567-018-0141-9, published online 21 May 2018.

In the version of this Article originally published, A. Mollén's affiliation was incorrectly denoted as number 10; it should have been 1. Throughout the Article, the tilde symbol above $b$ was too high to be visible. In the second column of page five, the superscript 2 in $\kappa \equiv\left(\left(\epsilon_{t} / \tilde{b}_{10}\right)^{2}\right)$ was also too high to be visible. Finally, the citation to ref. ${ }^{35}$ on page one of the Supplementary Information was incorrect; it should have been to ref. ${ }^{36}$. These issues have now been corrected.

\section{Publisher Correction: Topological quantum phase transition in the Ising-like antiferromagnetic spin chain $\mathrm{BaCO}_{2} \mathrm{~V}_{2} \mathrm{O}_{8}$}

Quentin Faure, Shintaro Takayoshi, Sylvain Petit, Virginie Simonet, Stéphane Raymond, Louis-Pierre Regnault, Martin Boehm, Jonathan S. White (D), Martin Månsson, Christian Rüegg, Pascal Lejay, Benjamin Canals, Thomas Lorenz, Shunsuke C. Furuya, Thierry Giamarchi (D) and Béatrice Grenier

Correction to: Nature Physics https://doi.org/10.1038/s41567-018-0126-8, published online 7 May 2018.

In the version of this Letter originally published, the year for ref. 30 was incorrectly listed as 2009; it should have been 2004.

This has now been corrected. 